\title{
Efektivitas Bimbingan Tugas Mahasiswa dalam Melakukan Asosiasi Fenomena Fisis dan Merumuskan Model Matematika Sederhana pada Mata Kuliah Kajian Fisika II
}

\author{
Djeli Alvi Tulandia) \\ Program studi pendidikan fisika, Universitas Negeri Manado Sulawesi Utara \\ Email: a)d.tulandi@yahoo.co.id
}

\begin{abstract}
The purpose of this research is: 1) to know the ability of student group to associate fact or phenomenon that is conceptually relevant physically with component of general phenomenon, 2) analyze data and describe graph relation between variables in context, 3) Formulate mathematical model of variable relationship observed and compare with concept relevant. The research design used is descriptive analytic with research design Treatment by Subject Design. Data analysis used is quantitative analysis to describe ability and development ability of student group in: 1) associate fact or phenomenon that is conceptually relevant physically with component of general phenomenon and describe it, 3) Create and describe graph relation among variable at context, 4) Formulate Mathematical models of observed variable relationships, 5) analyzing group work from initial to final meeting, using averages and variance. The result of the research shows that the guidance of the completion of student tasks with the pattern of repetitive examination of duties along with the evaluation of both individual and group effectively improve the students' ability from the initial meeting until the final meeting, although at the beginning of the meeting the ability of the students is still low. Meanwhile, the interview result shows that the students are not familiar with the tasks that relate the relationship of physics concepts taught in the classroom with the observation data of natural phenomena, as well as the density of other subjects tasks make limited time for task completion but this task gives experience to the students explaining the physical variables.
\end{abstract}

Keywords: Associate phenomenon, analyze, simple mathematical model.

\begin{abstract}
Abstrak
Tujuan penelitian ini adalah 1) Mengetahui kemampuan kelompok mahasiswa mengasosiasikan fakta atau fenomena yang relevan secara konseptual fisis dengan komponen fenomena umum, 2)Menganalisis data dan mendeskripsikan grafik hubungan antar variabel pada konteks, 3) Merumuskan model matematik hubungan variabel yang diamati dan membandingkan dengan konsep relevan. Rancangan penelitian yang digunakan yaitu deskriptif analitik dengan desain penelitian Treatment by Subject Design. Analisis data yang digunakan yaitu analisis kuantitatif untuk mendeskripsikan kemampuan dan perkembangan kemampuan kelompok mahasiswa dalam: 1)mengasosiasikan fakta atau fenomena yang relevan secara konseptual fisis dengan komponen fenomena umum dan mendeskripsikannya, 3) Membuat dan mendeskripsikan grafik hubungan antar variabel pada konteks, 4) Merumuskan model matematik hubungan variabel yang diamati, 5) menganalisis kerja
\end{abstract}


kelompok dari pertemuan awal hingga akhir, dengan menggunakan rataan dan varians. Hasil penelitian menunjukan bahwa pembimbingan penyelesaian tugas mahasiswa dengan pola pemeriksaan tugas secara berulang disertai evaluasi baik individu maupun kelompok efektif meningkatkan kemampuan mahasiswa dari pertemuan awal sampai pertemuan akhir, walaupun di awal pertemuan kemampuan mahasiswa masih rendah. Sementara itu hasil wawancara menunjukan bahwa mahasiswa belum terbiasa dengan tugas yang mengkaitkan hubungan konsep fisika yang diajarkan di kelas dengan data pengamatan fenomena alam, juga padatnya tugas matakuliah lain membuat waktu terbatas untuk penyelesiaan tugas namun tugas ini memberi pengalaman kepada mahasiswa menjelaskan variabel-variabel fisis.

Kata-kata Kunci: Mengasosiasi fenomena, menganalisis, model matematik sederhana.

\section{PENDAHULUAN}

Realitas penyelenggaraan pendidikan di program studi pendidikan Fisika UNIMA menujukkan bahwa waktu penyelesaian studi maupun penguasaan kompetensi mahasiswa memperlihatkan variasi yang cukup besar. Sebagian besar mahasiswa selain masa studinya lebih dari empat tahun, penguasaan kompetensi sebagai calon guru (penguasaan materi, metode evaluasi dan pembelajaran, dan penelitian) tergolong kurang. Di sisi lain mahasiswa yang berprestasi dan ikut dalam penelitian kolaborasi dengan dosen pada umumnya menyelesaikan studi dalam waktu empat atau kurang dari empat tahun (Medellu, 2015). Refleksi penyelenggaraan perkuliahan menunjukkan bahwa pemberian tugas kuliah belum secara sistematik mendukung pengembangan komprehensif kompetensi mahasiswa. Tim dosen dalam memberikan tugas hanya menekankan penguatan konsep/pengetahuan dalam matakuliah yang diampu dan kurang membangun kemandirian mahasiswa dalam mengembangkan secara mandiri konsep dan hubungan konsep dengan konteks dan lainnya. Selanjutnya berdasarkan data di jurusan menunjukkan bahwa kebanyakan mahasiswa mengalami kesulitan untuk merumuskan materi penelitian yang bermutu dan berdaya guna. Materi penelitian sebagian mahasiswa tidak memberikan pengalaman komprehensif terkait kompetensinya sebagai calon guru, antara lain merancang materi pembelajaran, mengembangan alternatif-alternatif kegiatan belajar dan evaluasi, melaksanakan pembelajaran dan melakukan evaluasi proses. Proses untuk mengoptimalkan kemampuan dan pengalaman terkait dengan kompetensi mahasiswa dapat dilakukan melalui tugas bejenjang.

Tugas berjenjang merupakan tugas yang diberikan kepada mahasiswa melalui matakuliah strategis. Tugas ini dirancang agar secara bertahap membangun kompetensi atau kemampuan profesi guru bagi mahasiswa khususnya mahasiswa program studi pendidikan fisika. Rancangan tugas berjenjang berpotensi mensinergikan (menggabungkan) dan menjamin koherensi tugas dari semester ke semester, dalam membangun pengalaman profesi guru fisika. Hal ini akan menjamin efisiensi dan produktivitas pembelajaran (Tulandi, 2015). Pemberian tugas berjenjang ini dilakukan sebagai bagian dari upaya meningkatkan penyelenggaraan perkuliahan yang disiplin dan bermutu untuk membangun kemampuan dasar keilmuan yang kuat, kemandirian, kreatifitas dan transferable skills yang tinggi bagi lulusan sebagai tenaga professional yang siap pakai dan siap beradaptasi dan mengembangkan profesinya.

Matakuliah kajian fisika II merupakan matakuliah wajib di prodi pendidikan fisika UNIMA yang bertujuan antara lain untuk memantapkan penguasaan konsep fisika SMP - SMA/SMK, Fisika Dasar melalui kegiatan membangun kebiasaan melakukan pengamatan fenomena/peristiwa alam untuk mengkaji, menganalisis dan melakukan asosiasi hubungan konteks- konsep yakni menjelaskan variabel-variabel fisis hasil pengamatan dengan konsep fisika yang diajarkan di kelas.

Kepada mahasiswa diberi tugas mengamati air terjun yang berada $\pm 8 \mathrm{~km}$ dari kampus. Pemberian tugas kepada mahasiswa dalam melakukan asosiasi fenomena fisis dan merumuskan model matematika sederhana juga merupakan bagian dari tugas berjenjang yang diterapkan di prodi pendidikan fisika UNIMA. Melalui pemberian tugas ini diharapkan secara bertahap mahasiswa akan melakukan tugas pengembangan materi (dan pemantapan materi untuk dirinya sendiri), pengembangan pilihan kegiatan pembelajaran (metode/ model pembelajaran yang relevan dengan materi), pengembangan evaluasi komprehensif/otentik, perancangan pembelajaran dengan berbagai pilihan pendekatan (laboratories, lapangan, lab virtual) sesuai karakteristik materi dan pada akhirnya 
menjadi produk rancangan instruksional yang dikerjakan secara mandiri dan hal ini memenuhi karakteristik proses pembelajaran yang bersifat interaktif, holistik, integratif, saintifik, kontekstual, tematik, efektif, kolaboratif, dan berpusat pada mahasiswa sebagaimana yang dimaksud oleh peraturan menteri riset, teknologi, dan Pendidikan Tinggi Republik Indonesia no. 44 tahun 2015.

Agar lebih mempermudah penalaran peserta didik dalam memahami gejala yang ada di alam, maka perlunya pembiasaan dalam melakukan pembelajaran yang memanfaatkan alam sekitar. Pembelajaran tentang alam, dapat melatih peserta didik agar mengamati secara langsung kejadian atau fenomena alam di sekitar. Kegiatan pengamatan, pengukuran di lapangan dapat meningkatkan penguasaan/ pemahaman mahasiswa terhadap obyek yang dipelajari sekaligus membangun penguasaan prosedur dan proses mempelajari obyek di alam (Silangen, 2015).

Tujuan pembelajaran fisika itu sendiri, yaitu mengembangkan kemampuan bernalar dalam berpikir analisis induktif dan deduktif dengan menggunakan konsep dan prinsip fisika untuk menjelaskan berbagai peristiwa alam dan menyelesaikan masalah baik secara kualitatif dan kuantitatif (Hariawan, dkk. 2014).

Pembelajaran fisika tidak lepas dari alam sekitar, beberapa kasus pada fisika tidak hanya dapat dijelaskan melalui persamaan atau rumus, tapi bisa dipahami dengan pemberian pengalaman langsung kepada mahasiswa untuk mempelajari hubungan sebab akibat antara faktor yang mempengaruhi atau mengendalikan fenomena fisis. Penguasaan mahasiswa terhadap hubungan faktor dengan fenomena serta kemampuan mendeskripsikan hubungan konteks dengan konsep akan memberikan penguatan dan penguasaan konsep fisika secara utuh (Silangen 2015). Prinsip pembelajaran menurut permen Nomor 103 tahun 2014 menjelaskan bahwa perserta didik difasilitasi untuk mencari tahu, peserta didik harus belajar dari berbagai sumber dan proses pembelajaran menggunakan pendekatan ilmiah.

Pembelajaran asosiatif adalah pembelajaran yang muncul ketika sebuah hubungan dibuat untuk menghubungkan kedua peristiwa (Vira 2013). Menurut (Tiara 2014) Pembelajaran asosiatif adalah pembelajaran bahwa dua kejadian saling terkait (associated). Pembelajaran asosiatif terjadi ketika peserta didik mengasosiasikan atau mengaitkan kejadian yang menyenangkan dengan pembelajaran.

\section{METODE PENELITIAN}

Penelitian ini adalah penelitian analitik deskripstif dalam menganalisis proses pembimbingan penyelesaian tugas mahasiswa dalam melakukan asosiasi fenomena fisis dan merumuskan model matematika sederhana pada matakuliah kajian fisika II melalui kegiatan mendeskripsikan hubungan antar variabel komponen fenomena, mendeskripsikan grafik, membuat asosiasi hubungan kontekskonsep, merumuskan model matematika sederhana peristiwa alam air terjun dan mendeskripsikan capaian, potensi dan hambatan yang dialami mahasiswa dalam pengembangan materi tugas. Dengan menggunakan rancangan sama subjek (treatment by subject) (Dimitrov \& Rumrill 2005 dalam Solang 2015).

Penelitian dilaksanakan di Jurusan Fisika, Pendidikan Fisika, Universitas Negeri Manado, bulan Februari- Juni 2016 pada mahasiswa semester IV yang kontrak matakuliah Kajian Fisika II Pendidikan Fisika.

Teknik analisis data dalam penelitian ini mengunakan deskriptif (kuantitatif). Skema rancangan penelitian sama subjek (Treatment by Subject Design) (Dimitrov dan Rumrill) dalam Solang (2015) dapat dilihat pada GAMBAR 1 dengan keterangan gambar sebagai berikut.

Keterangan:

S1 = Subjek Penelitian

$\mathrm{T} 2=$ Treatment II

$\mathrm{E} 1=$ Evaluasi pertama peneliti

$\mathrm{En}=$ Evaluasi ke- $n$

$\mathrm{F} 2=$ Fasilitas kedua

\author{
$\mathrm{T} 1=$ Treatment I (Perlakuan pertama dari peneliti) \\ $\mathrm{Tn}=$ Treatment ke-n \\ $\mathrm{E} 2=$ Evaluasi kedua \\ F1 $=$ Fasilitas pertama peneliti
}




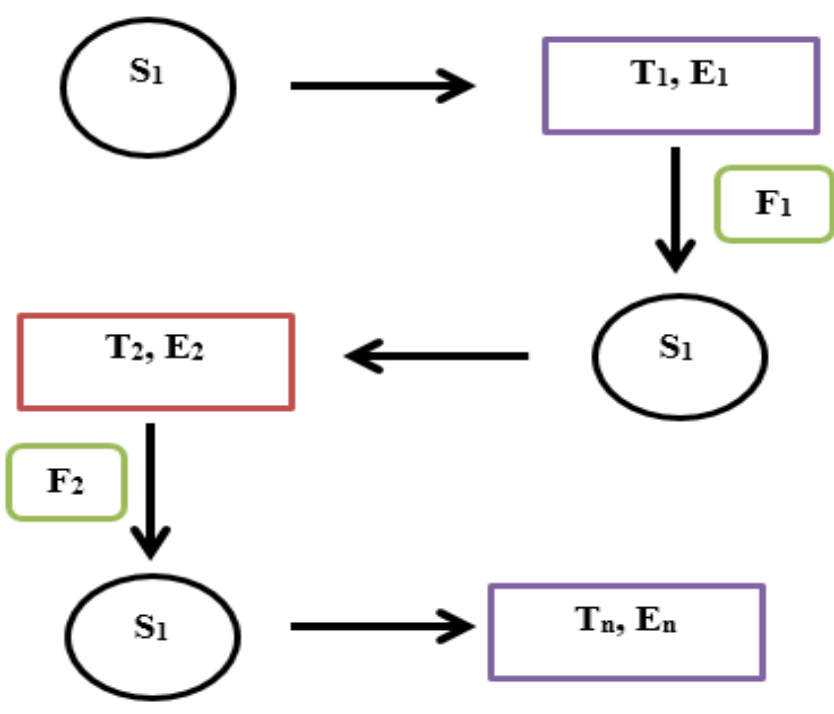

GAMBAR 1. Rancangan Penelitian Sama Subjek

\section{HASIL DAN PEMBAHASAN}

Penyelesaian tugas oleh mahasiswa lebih banyak dikerjakan dalam kelompok-kelompok kecil mahasiswa. Pembagian kelompok dilakukan secara acak, yakni dengan meminta mahasiswa menghitung 1 sampai 4, dan semua yang bernomor 1 masuk kelompok 1 dan seterusnya sampai kelompok 4. Setiap kelompok beranggotakan 6 orang. Tugas -tugas yang diberikan kepada subjek penelitian untuk mengidentifikasi, mengasosiasi, mendeskripsikan, menganalisis dan menyusun model matematika sederhana, mereka mengerjakan tugas sesuai tahapan dan mengisi format. Mendahului pemberian tugas, diberi gambaran/penjelasan bagaimana menyelesaikan tugas. Tugas yang diberikan mula-mula dikerjakan oleh subjek, kemudian diperiksa oleh dosen/tim pakar kemudian dikembalikan disertai saran dan masukan tertulis (treatment), mahasiswa merevisi dan melengkapi kembali, diserahkan lagi untuk diperiksa dan ini berlangsung sampai 3 kali atau sampai hasilnya dianggap sudah baik. Proses penyelesaian tugas tetap dikontrol dan diawasi oleh peneliti dan juga dilakukan wawancara dengan mahasiswa untuk melihat kesulitan dan hambatan serta hal-hal positif dalam menyelesaikan tugas.

Mahasiswa melakukan survey awal di air terjun Pinaras berjarak $20 \mathrm{~km}$ dari kampus untuk menentukan titik-titik/lokasi pengambilan data, kemudian pada hari berikutnya dilakukan pengamatan/pengambilan data. Hasil analisis diperlihatkan pada GAMBAR 2 berikut.
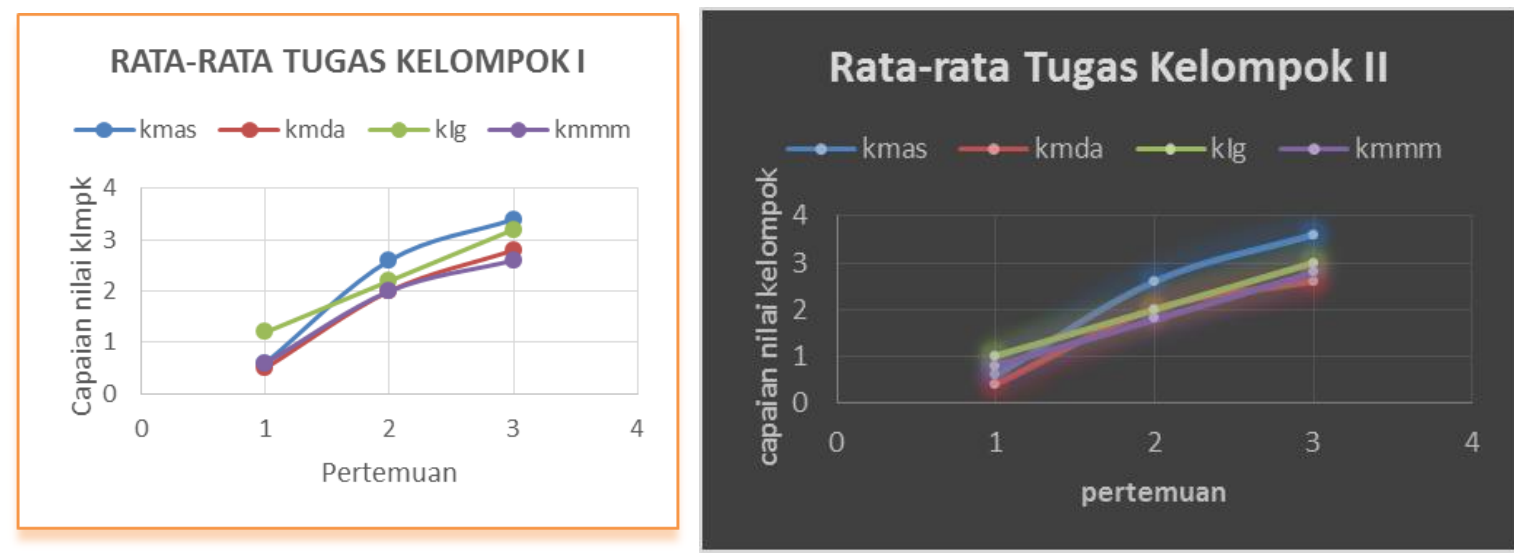

GAMBAR 2. Grafik capaian belajar kelompok

Keterangan kmas: kemampuan membuat asosiasi; kmda: kemampuan mendeskripsikan asosiasi;klg: kemampuan menginterpretasi grafik;kmmm: kemampuan merumuskan model matematik sederhana. 
GAMBAR 2 di atas memberi informasi bahwa umumnya mahasiswa memperoleh nilai rendah pada evaluasi pertemuan I karena mahasiswa belum terbiasa dengan penyelesaian tugas demikian, disamping interaksi belajar kelompok belum efektif. Hasil penyelesaian tugas I, diberi masukan dan saran oleh dosen pakar untuk diperbaiki/ dilengkapi dan diberi tugas tambahan untuk dievaluasi di pertemuan II. Hasil pertemuan II menunjukkan ada peningkatan, walaupun belum mencapai nilai standar terutama untuk tugas mendeskripsikan asosiasi dan merumuskan model matematika sederhana.

Mahasiswa mengamati bahwa air mengalir dari tempat tinggi ke tempat rendah melalui sungai dengan dasar miring. Mahasiswa mengamati bahwa kecepatan air berbeda untuk sungai yang dasarnya landai dan agak curam. Mahasiswa dapat mengasosiasi fenomena ini dengan percobaan gerak di bidang miring. Namun belum mampu menjelaskan secara baik percobaan di bidang miring dengan menuliskan persamaan percepatan benda dengan koefisien. Mahasiswa belum mampu mendeskripsikan dengan baik hubungan hukum Bernoulli dengan air yang mengalir di sungai dan seterusnya sehingga perlu dilanjutkan dengan tugas ketiga. Pada umumnya mahasiswa lemah pada menyusun model matematika sederhana dan mendeskripsikan asosiasi, seperti di tunjukan dengan grafik GAMBAR 2.

GAMBAR 3 berikut menggambarkan data aktivitas individu dan kelompok 1 dan 2 dalam menyelesaikan tugas membuat asosiasi, mendeskripsikan, menginterpretasi grafik dan merumuskan model metatik sederhana.

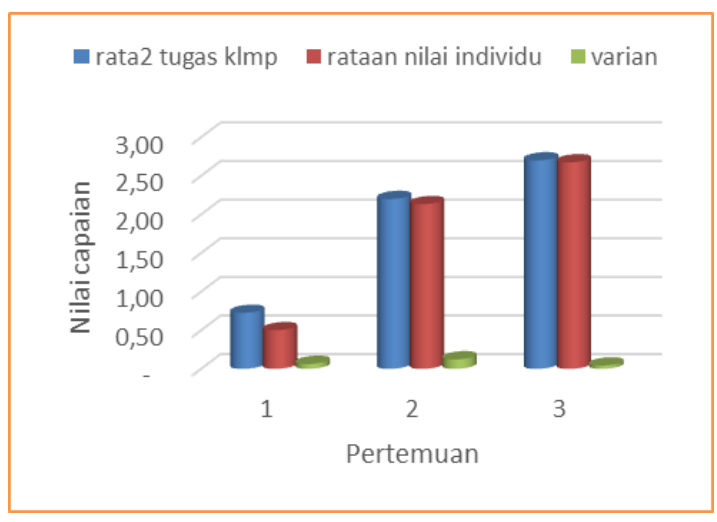

GAMBAR 3.a. Rata-rata capaian pada pertemuan 1,2, dan 3 kelompok-1

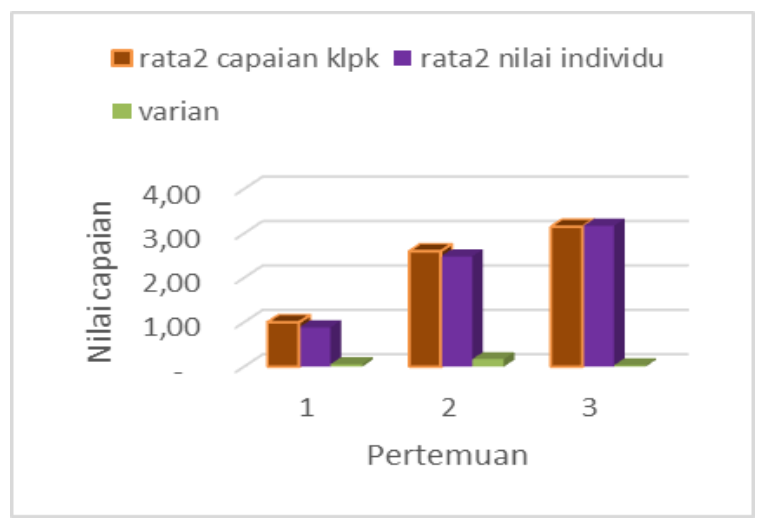

GAMBAR 3.b. Rata-rata capaian pada pertemuan 1,2, dan 3 kelompok-2

Secara umum informasi dari GAMBAR 3. menunjukkan bahwa baik nilai individu maupun kelompok mengalami peningkatan dari pertemuan ke-1 sampai pertemuan ke-3. Hal ini menunjukkan bahwa saran-saran dan arahan yang diberikan saat pembimbingan pada setiap pertemuan berjalan lancar. Pada pertemuan pertama umumnya rata-rata nilai capaian rendah. Hal ini disebabkan karena mahasiswa belum terbiasa dengan tugas-tugas demikian. Selanjutnya dari pertemuan-kepertemuan interaksi kerja kelompok semakin baik hal ini ditunjukkan dari nilai varians dari pertemuan satu sampai pertemuan ke-3 cenderung semakin rendah.

GAMBAR 3 menunjukkan perkembangan capaian penyelesaian tugas mahasiswa yang mengalami peningkatan sampai pertemuan III hal ini karena pengalaman mahasiswa yang sudah melewati tahap sebelumnya juga karena kerjasama tim sudah terbangun dan proses pembimbingan berjalan lancar. 


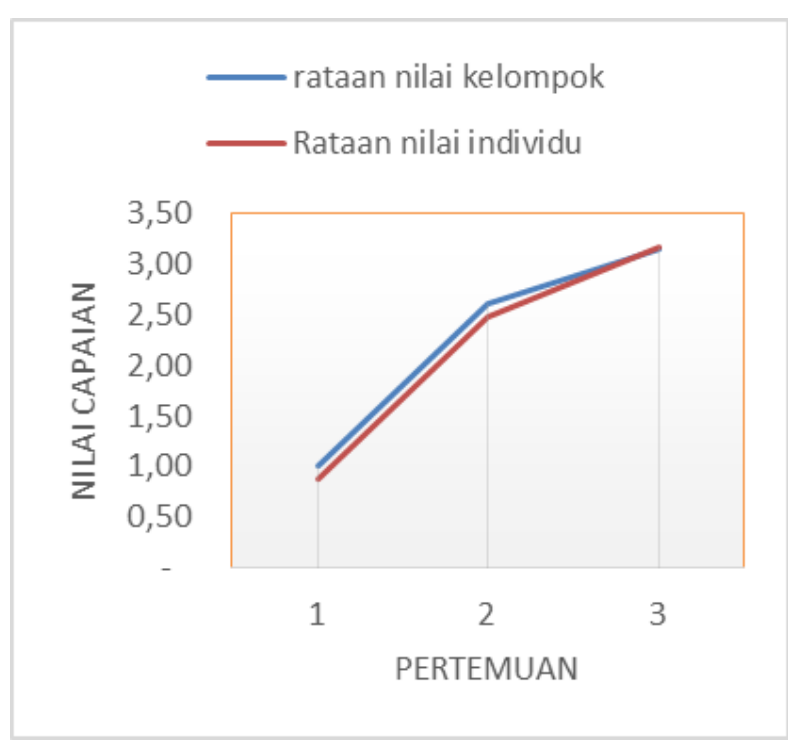

GAMBAR 4.a. Capaian nilai kelompok I dan Individu

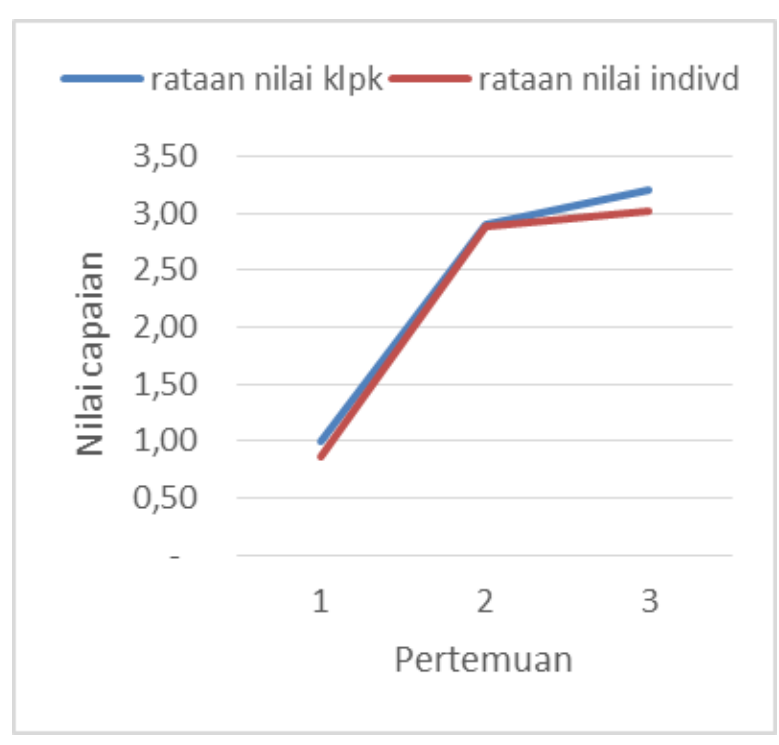

GAMBAR 4.b. Capaian nilai kelompok IV dan Individu

GAMBAR 4 di atas menginformasikan bahwa rataan nilai kelompk dan individu terus meningkat di setiap pertemuan. Kemudian baik kelompok I maupun kelompok IV nilai capaian kelompok lebih tinggi dari capaian nilai individu. Hasil ini sudah diprediksikan sebelumnya bahwa jika kerjasama tim berjalan lancar dimana diskusi intensif lancar hal ini berdampak pada peningkatan capaian pembelajaran hal ini sejalan dengan yang dikatakan oleh Michael Prince 2004 dalam review penelitiannya. Selanjutnya Tarricone \& Luca, 2002 menjelaskan bahwa kerjasama team yang efektif dapat mempengaruhi prestasi belajar. Adanya peningkatan nilai capain baik kelompok maupun individu menunjukkan bahwa pola pembimbingan tugas ysng diberikan efektif. Alison, B.2011, menjelaskan bahwa pembagian kelompok-kelompok kecil dalam pembelajaran jika difasilitasi dengan baik akan efektif dalam peningkatan pembelajarannya.

Kelompok yang anggotanya ada yang menonjol prestasinya hasil belajar kelompok tersebut lebih tinggi dari kelompok lain dengan anggota berkemampuan sedang/rendah. Hal ini wajar terjadi karena terjadi interaksi belajar kelompok yang berjalan lancar. Varians nilai individu dalam kelompok pada pertemuan ke-3 lebih rendah dari pertemuan sebelumnya. Hubungan antar pribadi (saling mengenal, saling menghargai, saling berbagi pengetahuan) mulai terbangun sejak pertemuan ke-2 dan pada pertemuan ke-3 hubungan antar anggota kelompok menjadi lebih familiar sehingga sharing pengalaman, sharing pengetahuan berjalan lancar.

Bedasarkan hasil wawancara peneliti kepada mahasiswa peserta kuliah kajian fisika sekolah-2 dengan tugas berjenjang diberikan, mahasiswa mengapresiasi positif pola penugasan yang dimulai dengan melakukan pengamatan di alam, mengisi format dan pengerjaan tugas secara berulang dengan bimbingan kontinu sehingga mahasisiwa mampu mengembangkan materi tugas secara mandiri, dan terbangun kerjasama tim. Kendala-kendala antara lain padatnya kegiatan mata kuliah lain, dan diawal kegiatan mahasiswa masih belum memahami dengan baik tugas yang diberikan walaupun sudah diberikan penjelasan oleh dosen. Memang di awal kegiatan mahasiswa masih mencari pengalaman dan berusaha memahami tugas.

\section{SIMPULAN}

Penyelesaian tugas mahasiswa dengan melakukan pengamatan di alam melalui kegitaan belajar kelompok dilengkapi format tugas yang jelas, kemudian pemberian tugas secara bertahap dan dipantau terus menerus menjadi efektif bagi mahasiswa mengembangkan kemandirian belajarnya. 


\section{REFERENSI}

Alison Burke.2011. How to Use Groups Effectivel. The Journal of Effective Teaching, Vol. 11, No. 2, 2011, 87-95.

Hariawan, Kamaluddin, Wahyono U. 2014. Pengaruh model pembelajaran creative problem solvingterhadap kemampuan memecahkan masalah fisika pada siswa kelas XI SMA Negeri 4 Palu. Jurnal Pendidikan Fisika Tadulako (JPFT) Vol. 1 No.2 ISSN 23383240.

Michael P.2004.Does Active Learning Work? A Review of the Research Journal of Engineering Education, 2004.

Peraturan menteri pendidikan dan kebudayaan Republik indonesia Nomor 103 tahun 2014.

Permen Ristek Dikti RI no. 44 tahun 2015 tentang Standar Nasional Pendidikan Tinggi.

Silangen P. 2015. Model Pengembangan danau Linow sebagai lab alam prodi fisika, konsentrasi geothermal FMIPA UNIMA. Laporan Penelitian Universitas Negeri Manado.

Solang, N. 2015. Efektivitas Pembelajaran Fisika Berbasis Masalah Menggunakan Simulasi/Animasi dalam Meningkatkan Hasil Belajar Siswa. Skripsi. Tondano: Jurusan Fisika Fakultas Matematika dan Ilmu Pengetahuan Alam, Universitas Negeri Manado.

Tarricone \& Luca, 2002. Successful teamwork: Herdsa 2002. Conference Proceedings. Edith Cowan University, Perth.

Tiara R Balqish. 2014. Pendekatan behavioral dan kognitif sosial. http://13029rtb.blogspot. co.id/2014/06/normal-0-false-false-false-in-X-none-X_3427.html diakses 20 september 2015

Tulandi,D. 2015. Model tugas berjenjang untuk meningkatkan efisiensi, produktivitas dan mutu proses pembentukan kompetensi mahasiswa program studi pendidikan fisika fmipa UNIMA.Laporan penelitian hibah unggulan perguruan tinggi tahun I.

Vira A. 2013. Classical conditioning dan operant conditioning dalam pembelajaran bahasa Inggris. http://amandavira.blogspot.co.id/2013/04/makalah-classical-conditioning-dan.html diakses 20 september 2015. 
